\title{
PROSPECTS OF COOPERATION BETWEEN RUSSIAAND THE COUNTRIES OF THE MAGHREB IN THE LIGHT OF NEW GLOBAL CHALLENGES
}

\author{
Natalya A. Zherlitsina \\ Candidate of Sciences (History), Senior Researcher, \\ Institute for African Studies, Russian Academy of Sciences \\ ns_inafr@mail.ru \\ Spiridonovka St., 30/1, 123001 Moscow, Russian Federation
}

\begin{abstract}
The article examines the new realities of Russia's foreign policy after the "Arab Spring" and the potential for increased Russian influence in the Maghreb. One of the consequences of the recent political upheavals in North Africa is the growth of terrorist threat - this factor draws particular attention to this region. The Maghreb is important for the promotion of Russian interests in the Arab world and the African continent. Russia and North Africa are seeking strategic cooperation, and these countries have long-term friendship and mutual interests in the political and economic spheres. Further increase of the interaction will strengthen bilateral relations, will make it easier to survive during the political and economic crisis. The article analyzes the formation, the current state and prospects of Russian-Algerian, Moroccan-Russian and Russian-Tunisian relations. Algeria is one of the leading economic partners of Russia on the African continent. The main areas of bilateral cooperation are the energy and military spheres. The growth of the terrorist threat in the Sahara-Sahel region prompted Russia and Morocco to deepen security cooperation. In the context of EU economic sanctions against Russia a priority in RussianTunisian and Russian-Moroccan trade relations is to enhance cooperation in the field of agriculture. Russia is a traditional exporter of Moroccan oranges and Tunisian olive oil. Promising areas of cooperation of Russia and Tunisia are the development of water resources and hydraulic engineering, infrastructure projects in the field of construction of roads, bridges, industrial facilities. Expansion of ties with the North African countries will allow Russia to increase influence in the region.
\end{abstract}

Key words: "Arab spring", international terrorism, radicalization, Russian-Arab cooperation, trade, investments.

\section{ПЕРСПЕКТИВЫ СОТРУДНИЧЕСТВА РОССИИ СО СТРАНАМИ МАГРИБА В СВЕТЕ НОВЫХ ГЛОБАЛЬНЫХ ВЫЗОВОВ}

\footnotetext{
Наталья Александровна Жерлицына

Кандидат исторических наук, старший научный сотрудник, Институт Африки Российской Академии наук ns inafr@mail.ru

Аннотация. В статье исследуются новые реалии российской внешней политики после «арабской весны» и перспективы усиления российского влияния в Магрибе. Одним из последствий недавних политических катаклизмов в Северной Африке стал рост террористической опасности - фактор, привлекающий особое внимание к этому региону, являющемуся ключевым для продвижения российских интересов в арабском мире и на Африканском континенте. Россия и страны Северной Африки стремятся к стратегическому сотрудничеству, их связывают многолетняя дружба и взаимные интересы в политической и экономической сферах. Расширение спектра взаимодействия укрепит двусторонние отношения, позволит в будущем менее

() болезненно переживать кризисные периоды как в экономическом, так и в политическом плане. В статье дан
} 
анализ становления, современного состояния и перспектив российско-алжирских, российско-марокканских и российско-тунисских отношений.

Ключевые слова: «арабская весна», международный терроризм, радикализация, российско-арабское сотрудничество, торговля, инвестиции.

В условиях переориентации российской внешней политики эффективность внешнеэкономических связей России зависит от расширения круга партнеров, и страны Магриба представляются весьма перспективным направлением. Северная Африка является ключевым регионом для продвижения экономических, политических, глобальных интересов России в арабском мире, на Африканском континенте и Средиземноморье. Достижение мира и укрепление стабильности в этой части мира, обеспечение безопасности транспортных артерий прямо отвечают российским геополитическим интересам.

АНДР входит в тройку ведущих экономических партнеров России на Африканском континенте. Значительный топливно-сырьевой потенциал, быстрорастущее население Алжи$\mathrm{pa}$, его устойчивая и динамично развивающаяся экономика выдвигают эту страну в число новых лидеров арабо-мусульманского мира. Королевство Марокко и РФ рассматривают друг друга в качестве потенциальных стратегических партнеров. Интенсивный политический диалог ведется по основным вопросам, затрагивающим взаимные интересы: ситуация на Ближнем Востоке и Северной Африке, Средиземноморье. Для РФ Марокко важна как активный актор в Сахаро-Сахельской зоне, важном, перспективном районе, в котором сосредоточены огромные запасы ископаемых. По итогам 2014 г. Королевство Марокко стало вторым по объемам товарооборота торговым партнером РФ на Африканском континенте. Тунисская Республика - проверенный временем партнер Российской Федерации в регионе Северной Африки и Ближнего Востока, одна из наиболее развитых стан Северной Африки.

Нынешний подъем в российско-арабских отношениях стал возможным благодаря прочному фундаменту доверия и дружбы, заложенному несколько десятилетий назад. Поддержка Советским Союзом на международной арене оказала положительное влияние в деле предоставления независимости Алжиру, Ма- рокко и Тунису и заложила основу для дальнейшего развития дружественных отношений. Молодые независимые страны нуждалась в помощи для ликвидации последствий колониализма, восстановления национальной экономики. СССР, руководствуясь идеологическими императивами, выступал в качестве донора экономической и военно-технической помощи для потенциальных единомышленников, содействуя их развитию. С Алжиром, избравшим некапиталистический путь развития, у СССР установились особые отношения, ему были предоставлены государственные кредиты на цели экономического развития в размеpe 2 млрд долл., помощь СССР направлялась на развитие ряда отраслей народного хозяйства, прежде всего - промышленности, преимущественно тяжелой [3, с. 132]. Связывало страны и тесное военно-техническое сотрудничество. В Марокко и Тунисе при содействии Советского Союза были построены важные в экономическом и социальном плане предприятия энергетической, горнорудной и гидротехнической промышленности. Значительное место в сотрудничестве СССР и стран Магриба занимала подготовка национальных кадров для различных областей экономики молодых независимых стран.

После распада СССР влияние и присутствие России в этом регионе ослабли, а политика во многом утратила четкие очертания. Россия отказалась от идеологических приоритетов в сфере межгосударственных отношений и совершила переход к рыночному регулированию внешнеэкономических и торговых связей с зарубежными странами, включая и традиционных арабских партнеров. Активизация политических контактов, начавшаяся в конце 1990-х гг., увенчалась обменом визитами на высшем уровне и подписанием Деклараций о стратегическом партнерстве - программных документов, определяющих отношения между странами на современном этапе.

Алжир стал первым арабским государством, с которым Россия подписала подобное соглашение во время визита президента 
АНДР А. Бутефлики в Москву в апреле 2001 года. Этот визит придал новое качество двусторонним связям и стал толчком для возобновления экономического сотрудничества между Россией и Алжиром. Со стороны правительств двух стран и представителей крупного бизнеса были предприняты конкретные шаги в данном направлении. В результате торговый обмен между РФ и АНДР за период с 2001 по 2006 г. увеличился с 203 до 591 млн долл. [1]. Ответный визит президента РФ В.В. Путина в АНДР в 2006 г. придал новый импульс российско-алжирскому сотрудничеству во всех областях. Соглашения, достигнутые в энергетической области, позволили говорить о начале стратегического партнерства России и Алжира в этой сфере. Контакты на высшем уровне продолжились в 2008 и 2010 гг., когда стороны обменялись визитами президентов А. Бутефлики и Д.А. Медведева. В ходе переговоров стороны договорились о реализации конкретных проектов в сфере энергетики и военно-технического сотрудничества.

Между РФ и Королевством Марокко в 2000-х гг. продолжился интенсивный политический диалог, наладившийся еще в советское время. Важным итогом официального визита в Москву в октябре 2002 г. короля Марокко Мухаммеда VI стало подписание Декларации о стратегическом партнерстве, ставшей основой для дальнейшего расширения взаимодействия. Президент В.В. Путин и король Мухаммед VI встречались также в 2003 г. на полях саммита Организации исламская конференция. В 2006 г. впервые в истории двусторонних отношений глава России посетил Марокко и, как следствие, двусторонние отношения интенсифицировались по всем направлениям. Для Марокко важно, что Россия в качестве постоянного члена СБ $\mathrm{OOH}$ оказывает непосредственное влияние на процесс решения одного из острейших и длительных региональных конфликтов - проблемы Западной Сахары. РФ выступает за политический диалог всех сторон конфликта, за обоюдно приемлемое правовое решение, поддерживает позицию СБ ООН о необходимости проведения референдума, представители России входят в состав Миссии $\mathrm{OOH}$ в Западной Сахаре. За последующие годы дальнейшее развитие получило двустороннее сотрудниче- ство в традиционных областях взаимодействия - внешнеполитической, торгово-экономической, культурной, морском рыболовстве, туризме. За это же время дан старт сотрудничеству в новых сферах - космосе, военнотехническом сотрудничестве. Наметились и другие направления - например, атомная и традиционная энергетика.

В последние несколько лет Северная Африка непрерывно привлекает внимание международного сообщества, что связано с появлением новых вызовов и угроз. Череда арабских революций, социально-политических потрясений, политический хаос, война с международным терроризмом и гуманитарные кризисы, связанные с незаконной миграцией, заставили внести коррективы в свой внешнеполитический курс многие страны мира, в том числе и Россию. Проблемы безопасности в Северной Африке и на Ближнем Востоке стали главной темой переговоров министра иностранных дел РФ С.В. Лаврова с тунисским коллегой М. Хамди в Москве в сентябре 2014 года. На пресс-конференции в МИД РФ по итогам переговоров С. Лавров отметил: «У нас общая решимость объединять усилия в двустороннем плане и в многосторонних форматах, чтобы более решительно и эффективно бороться с главной угрозой региона Ближнего Востока и Северной Африки - угрозой международного терроризма» [9].

Тунис, родина «арабской весны», стал, после череды испытаний положительным символом арабских демократических перемен и самой большой надеждой в регионе на построение первой современной демократии в арабском мире. По словам посла Туниса в РФ А. Гутали, Тунис «дает пример мирного перехода к демократии, он показал, что это возможно в арабо-исламской стране» [7]. Хотя результаты парламентских и президентских выборов конца 2013 г. являются положительными для страны, но их еще рано воспринимать как выбор населения в пользу светского развития, демократия в Тунисе остается весьма хрупкой. Внутренние вызовы и нерешенные проблемы дополняются вновь возникающими извне угрозами безопасности страны. Тунисская Республика одной из первых испытывает на себе новый, более жесткий натиск экстремизма, сегодня Тунис оказался зажатым в тисках радикаль- 


\section{МЕЖДУНАРОДНЫЕ ОТНОШЕНИЯ}

ных исламистских группировок, действующих в Ливии и на границах с Алжиром. Серьезный вызов тунисской государственности - радикализация молодежи. МВД Туниса сообщает, что 2400 его граждан стали боевиками с 2011 г. [6]. Основными причинами активного исхода молодежи Туниса на джихад являются безработица, тяжелое экономическое положение в стране, грамотная, интенсивная вербовка и доступность пропагандистских материалов в интернете. Тунис стал лидером поставщиков рекрутов для самой одиозной террористической организации современности - Исламского Государства (далее - ИГ).

Беспокойство международного сообщества вызывают попытки ИГ закрепиться на территории Марокко. Радикалы используют географическую близость Королевства к Европе, чтобы в той или иной форме вовлечь в джихад и Старый Свет. Цель террористов создать эмират исламского халифата в странах Магриба. Марокканские спецслужбы утверждают, что террористическая группировка «Джунд аль-Халифа», связанная с ИГ и ранее действовавшая на территории Алжира, предпринимает активные шаги для распространения влияния в стране. Глава Центрального бюро судебных расследований Марокко М. Хьям сообщил о 1354 марокканцах, присоединившихся к ИГ, из них 156 уже вернулись обратно в Марокко. 286 марокканцев погибли в Сирии и Ираке. Кроме того, 185 марокканских женщин вместе с 135 детьми присоединились к группировке [4].

Волна «арабской весны» обошла Алжир стороной. Алжирские военные, имеющие многолетний опыт вооруженной борьбы с терроризмом, смогли удержать ситуацию под контролем. Однако террористическая активность исламских боевиков в сахаро-сахельской зоне на границах с Мали, Нигером и Ливией стала региональной проблемой, с которой эти страны вряд ли смогут справиться без внешней помощи. В России высоко оценивают усилия Алжира по налаживанию антитеррористического сотрудничества в сахаро-сахельской зоне и готовы к взаимодействию на этом направлении.

Независимые и влиятельные союзники на Ближнем Востоке важны для России в условиях, когда она испытывает негативные последствия западных экономических санкций и падения цен на нефть. В непростой ситуации оказались и страны Магриба. Так, в АНДР, экономика которой крепко привязана к нефти и газу, составляющих львиную долю экспорта, значительное сокращение доходов может привести к острому кризису и подорвать систему «нефть в обмен на общественное спокойствие». В условиях политической нестабильности растет социальная напряженность и в арабских странах, импортерах нефти Марокко, Тунисе, Египте. Они столкнулись с двойным давлением: высокими расходами на импорт энергоносителей и продовольствия, сочетающимися с глобальным экономическим спадом. В условиях растущей безработицы, социальной нестабильности и завышенных ожиданий населения необходимо стабилизировать экономику и проводить реформы, которые в будущем обеспечат создание новых рабочих мест и всеобъемлющий рост. Госрасходы выросли из-за дополнительных трат на субсидирование продуктов питания и энергетики, а политические волнения нанесли удар по столь необходимым частным инвестициям, кроме того, сократились госрезервы. В Египте, например, дефицит бюджета вырос в 2013 г. до 12 \% ВВП [2].

Политические изменения в странах Северной Африки и корректировка российской внешней политики, связанная с негативными последствиями западных экономических санкций, открывают новые возможности для развития экономического партнерства стран. В условиях экономических санкций ЕС против России первоочередной задачей в российскотунисских и российско-марокканских торговых связях было названо расширение отношений в области сельского хозяйства. Стороны подчеркнули, что у тунисских и марокканских поставщиков появилась прекрасная возможность расширить свое присутствие на российском рынке. Тунис и Марокко располагают хорошими возможностями по замещению ряда товаров, которые Россия обычно закупала в Европе, например, оливкового масла и сельскохозяйственной продукции. Одним из итогов визита в Россию в сентябре 2014 г. министра торговли Туниса Н. Харруша и министра сельского хозяйства Л. Лашааля стало решение о поставках 300 тыс. т тунисского оливкового масла, а также ряда других про- 
дуктов в РФ. Товарооборот между Россией и Тунисом в 2014 г. вырос относительно 2013 г. на $44 \%$ и составил 1072 млн. долларов. Российский экспорт в Тунис в 2014 г. также увеличился до 1050 млн долл., что на 75 \% превышает цифру 2013 года.

Позитивным фактором для двусторонних отношений является желание Туниса присоединиться к Евразийскому экономическому союзу (далее - ЕАЭС). Присоединение к союзу позволит Тунису диверсифицировать экспорт, который ориентирован в основном на Европу, и торговать на более выгодных условиях. Тунис готов поставлять в Россию кроме традиционного оливкового масла финики, свежие овощи и фрукты, сыры, картофель, мясо птицы, сардины, молочную продукцию. Кроме того, участие в ЕАЭС также позволит Тунису привлекать инвестиции из стран союза.

Российский рынок представляет для Марокко стратегический интерес, являясь вторым по величине рынком сбыта продовольственной и сельскохозяйственной продукции из Марокко. В российском импорте из Марокко преобладают цитрусовые (49 \%), свежие овощи (20\%), трикотаж (15\%), обувь (5\%), рыбная мука и рыба (7 \%) [5]. Внешнеторговый оборот России и Марокко в 2014 г. вырос на $7 \%$ и достиг 1,5 млрд долларов. Положительное сальдо торгового баланса составило 338 млн долларов. Российский экспорт в Марокко за этот период составил 931 млн долларов, что на $8 \%$ превышает показатель 2013 года. Сотрудничество в области сельского хозяйства и рыболовства является одним из основных направлений взаимодействия двух стран. Марокканские сельхозпроизводители намерены приложить усилия, чтобы закрепиться на российском рынке. Наравне с традиционными экспортными товарами, такими как цитрусовые, томаты и другие овощи, марокканские производители намерены предложить России рыбу и морепродукты, оливковое и аргановое масла. С марокканской стороны было высказано намерение обратиться в ЕАЭС с предложением о создании зоны свободной торговли с Марокко. В королевстве рассчитывают, что произойдет увеличение экспорта марокканских фруктов в РФ. Для этого нужно решить проблему транспортировки: немалая часть марокканских товаров экс- портировалась через европейские страны, что повышало их цены. Стороны намерены развивать прямой канал поставок из Агадира в Санкт-Петербург. По нему будет поставляться большинство овощей и фруктов. Планируется также открыть в Санкт-Петербурге филиал марокканской организации по контролю за качеством и безопасностью продукции. Стороны также решают технологическую проблему доставки рыбы, выловленной российскими кораблями в марокканской рыболовной зоне, не замороженной, а охлажденной. Эксперты двух стран считают, что сближение РФ и Марокко в результате санкций стимулирует двустороннюю торговлю и позволит расширить возможности для создания новых рабочих мест в Марокко.

Действенными инструментами в выработке новых форматов взаимодействия двух стран и конкретных механизмов реализации достигнутых договоренностей стали Межправительственные комиссии по торгово-экономическому и научно-техническому сотрудничеству и Деловые советы, созданные в 2000-х гг. и действующие на двусторонней основе между Россией и странами Северной Африки.

Усилия, предпринимаемые Смешанной межправительственной Российско-Алжирской комиссией по торгово-экономическому и научно-техническому сотрудничеству и Российско-Алжирским деловым советом, позволили значительно повысить качество деловых контактов между представителями российских и алжирских бизнес-кругов. Российские компании получили возможности устанавливать прямые партнерские отношения с алжирскими предприятиями, развивать с ними научно-техническое сотрудничество, открывать совместные производства и участвовать в инвестиционных проектах. Новым направлением деятельности российского бизнеса в Алжире становится открытие сервисных центров крупных российских компаний, таких как «Уралвагонзавод», планируется открыть центр по буровым установкам, а также создать совместные предприятия по выпуску дорожной и строительной техники. Приоритетными направлениями российско-алжирского сотрудничества являются нефтехимия, электроэнергетика, атомная энергетика, водные ресурсы, строитель- 


\section{МЕЖДУНАРОДНЫЕ ОТНОШЕНИЯ}

ство, медицина и фармацевтика, авиация и авиастроение, пищевая промышленность. Так, сотрудничество с Алжиром в фармацевтической отрасли позволит России выйти на рынок третьих стран в Африке. Алжирская сторона рассматривает сферу жилищного строительства в качестве наилучшей площадки для развития российско-алжирского сотрудничества.

Выступая на открытии российско-алжирского бизнес-форума, председатель российской части РАлДС О.В. Сиенко подчеркнул важность развития российско-алжирских связей по всем сферам деловой активности с учетом особой значимости Алжира как ключевого партнера России в Северной Африке и арабском мире в целом [10]. РАлДС подготовил в качестве «дорожной карты» перечень первоочередных проектов на ближайшую перспективу, предусматривающий сотрудничество в электроэнергетике, нефтепереработке, реализацию масштабных проектов в сфере водного хозяйства Алжира, в том числе строительство нескольких крупных плотин с гидротехническими комплексами и резервуаров, проработку проекта поставок рыболовных судов российского производства, строительства объектов портового хозяйства и зерновых терминалов в алжирских портах.

Традиционной сферой российско-алжирского сотрудничества еще с советских времен является поставка различных систем вооружений для алжирской армии. До настоящего времени алжирская армия в достаточно большом количестве имеет на вооружении военную технику советского и российского производства и, соответственно, нуждается в ее модернизации, поставках запчастей. Несмотря на наметившуюся в последние годы тенденцию к сотрудничеству АНДР со странами НАТО, Алжир все еще остается вторым по значимости импортером российского оружия с долей в 14 \%. Так, по объемам заказов на поставку и производство танков Т-90С Алжир вплотную приближается к Индии и в ближайшей перспективе перекроет показатели индийско-российского сотрудничества в этой сфере.

В мае 2014 г. в Тунисе Российско-Тунисская межправительственная комиссия провела пятое заседание в рамках работы Россий-
ско-Тунисского Делового Форума. Представители бизнеса двух стран определили как перспективные направления сотрудничество в области освоения водных ресурсов Туниса и гидротехнического строительства, инфраструктурные проекты в сфере строительства дорог, мостов, промышленных объектов, поставки российской техники тунисским строительным компаниям, проведение геологоразведочных работ, строительство горно-обогатительных предприятий. Тунисская сторона представила на рассмотрение российским коллегам в качестве возможных сфер для инвестиций и сотрудничества проекты строительства контейнерного терминала в морском порту Радес и глубоководного порта в Энфиде, проект развития свободной экономической зоны в Бизерте, включающий модернизацию и расширение порта, строительство причала для яхт, набережной и жилого комплекса. Представители российской «Росэкологии» и тунисского предприятия «Sfaxi Moules» обсудили вопросы поставки в Тунис листовых полимерных материалов для организации совместного российско-тунисского производства локальных систем очистки бытовых и коммунальных вод. Привлекательной сферой для российско-тунисского сотрудничества может стать разработка минерально-сырьевой базы Туниса, особый интерес представляет месторождение фосфатов Сра-Уэртэн в провинции Кеф. Российские компании также проявляют интерес к реализации инфраструктурных проектов: прокладке железнодорожных путей и формированию железнодорожного кластера, строительству сети автодорог.

Еще до начала «арабской весны» тунисским правительством был утвержден план строительства к 2020-2023 гг. АЭС мощностью 900 МВт. «Росатом» выразил готовность к диалогу на предмет разработки проектов строительства. В апреле 2010 г. российская делегация провела в Тунисе Дни российских ядерных технологий. В 2015 г. между РФ и Тунисской Республикой был подписан меморандум о сотрудничестве в области мирного атома. Документ закладывает основу для взаимодействия сторон по широкому спектру вопросов: строительству и эксплуатации ядерных реакторов, фундаментальным и прикладным исследованиям, использованию изотопов 
в промышленности, медицине и сельском хозяйстве, подготовке специалистов в области ядерной физики и энергетики.

Гендиректор созданного в 2006 г. Российско-Марокканского делового совета С. Янковец выделяет основные направления для развития деловых контактов между РФ и Королевством Марокко: энергетику, туризм, инвестиции в инфраструктуру и продовольственную безопасность. Отдельным фактором роста совместной торговли может стать выстраивание надежных логистических схем и увеличение экспорта российских зерновых культур в Марокко [8]. Заинтересованность Марокко в привлечении российского бизнеса и технологий основана на намерении властей «уйти» от аграрно-сырьевой экономики. Новый этап реиндустриализации страны видится ее элитам с участием зарубежного, и в частности российского, бизнеса. Основные инвестиционные проекты, предлагаемые марокканской стороной российским партнерам - это освоение нефтеносных сланцев (Марокко находится в десятке крупнейших обладателей этого сырья), фосфоритов (5-е место в мире) и производство сжиженного газа. Гендеректор марокканского агентства поддержки экспорта Maroc Export 3. Maафири считает, что сферами, наиболее интересными для российских инвесторов, могут быть туризм и гостиничный бизнес, химическая промышленность, энергетика и фармацевтическая отрасль, в частности производство так называемых дженериков [11].

Таким образом, за последние годы России удалось, несмотря на политические катаклизмы, наладить активное сотрудничество с каждой из стран Магриба с учетом их специфики. Региональные трансформации 20112014 гг., несмотря на рост политических рисков и возникновение очагов политического хаоса, открыли России новые возможности для продвижения в странах Северной Африки. Для будущего двусторонних отношений особенно важно, что постепенно на первый план выходит сотрудничество в области современных технологий и инвестиционной деятельности. Расширяя свое присутствие в Северной Африке, в Средиземноморье, РФ имеет шансы стать важным игроком в условиях нового баланса сил в регионе, усилить российское влияние на формирование нового облика международных отношений, более эффективно противостоять главной угрозе современности - международному терроризму.

\section{СПИСОК ЛИТЕРАТУРЫ}

1. Алжиро-российские отношения. - Электрон. текстовые дан. - Режим доступа: http://www. algerianembassy.ru/Ambassade_ru.htm (дата обращения: 15.02.2015). - Загл. с экрана.

2. Арабская весна не помогла ближневосточным странам быстро улучшить состояние экономики: МВФ. - Электрон. текстовые дан. - Режим доступа: http://copdoc.ru/news/378.html (дата обращения: 27.05.2013). - Загл. с экрана.

3. Васильев, А. М. Россия на Ближнем и Среднем Востоке / А. М. Васильев. - М. : Наука, 1993. $392 \mathrm{c}$.

4. Герасименко, А. Марокко разоблачило отделение ИГИЛ. - Электрон. текстовые дан. - Режим доступа: http://daily-news.com.ua. (дата обращения: 25.03.2015). - Загл. с экрана.

5. Интервью замминистра с/х Марокко М. Садики Газете.ru. - Электрон. текстовые дан. - Режим доступа: http://www.gazeta.ru/business/news/2014/ 09/15/n_6481021.shtml (дата обращения: 15.09.2014). Загл. с экрана.

6. Карта показывает расползание ИГИЛ от Алжира до Афганистана. - Электрон. текстовые дан. - Режим доступа: http://asialive.info/2015/03/ karta_pokazyvaet_raspolzanie_igil_ot_alzhira_do afganistana 253144.html (дата обращения: 12.03.2015). - Загл. с экрана.

7. Круглый стол в МИА «Россия сегодня». Российско-Арабский деловой совет. - Электрон. текстовые дан. - Режим доступа: http://ria.ru/world/ 20141119/1034178133.html (дата обращения: 20.11.2014). - Загл. с экрана.

8. Марокко. ТПП РФ. - Электрон. текстовые дан. - Режим доступа: http://tpprf.ru/ru/vneshniesvyazy/vneshnie-svyazy-news/detail/?ID=45644 (дата обращения: 15.08.2015). - Загл. с экрана.

9. Новости. Тунис // Журнал «Международная жизнь». - Электрон. текстовые дан. - Режим доступа: https://interaffairs.ru/news/show/11717 (дата обращения: 03.09.2014). - Загл. с экрана.

10. Отношения России и Алжира имеют особый доверительный характер. - Электрон. текстовые дан. Режим доступа: http://www.council.gov.ru/presscenter/news/42891/ (дата обращения: 13.05.2014). - Загл. с экрана.

11. Парфенова, А. Марокко готовится расширять сотрудничество с Россией. - Электрон. текстовые дан. - Режим доступа: http://arafnews.ru/ news/razmeschenie-biznesa-v-marokko-otkryvaet- 


\section{МЕЖДУНАРОДНЫЕ ОТНОШЕНИЯ}

rossijskim-investoram-vyhod-na-ogromnyjafrikanskij-rynok.html (дата обращения: 29.10.2014). Загл. с экрана.

\section{REFERENCES}

1. Alzhiro-rossiyskie otnoshenia [AlgerianRussian Relations]. Available at: http://www. algerianembassy.ru/Ambassade_ru.htm. (accessed February 15, 2015).

2. Arabskaya vesna ne pomogla blizhnevostochnym stranam bystro uluchshit sostoyanie ekonomiki: MVF [Arab Spring Did Not Help the Middle East Countries to Quickly Improve the State of the Economy: IMF]. Available at: http:// copdoc.ru/news/378.html. (accessed May 27, 2013).

3. Vasilyev A.M. Rossiya na blizhnem i srednem vostoke [Russia in the Middle East]. Moscow, Nauka Publ., 1993. 392 p.

4. Gerasimenko A. Marokko razoblachilo otdelenie IGIL [Morocco Exposed the Department of ISIL]. Available at: http://daily-news.com.ua. (accessed March 25, 2015).

5. Intervyu zamministra s/kh Marokko M. Sadiki Gazete.ru. [Interview of Deputy Minister of Agriculture of Morocco M. Sadiki to the Gazeta.Ru]. Available at: http:/www.gazeta.ru/business/news/2014/09/15/ n_6481021.shtml (accessed September 15, 2014).

6. Karta pokazyvaet raspolzanie IGIL ot Alzhira do Afganistana [Map Shows the Spread of
ISIL From Algeria to Afghanistan]. Available at: http:/ /asialive.info/2015/03/karta_pokazyvaet_ raspolzanie igil_ot_alzhira_do_afganistana_253144.html. (accessed March12, 2015).

7. Kruglyy stol v MIA "Rossiya segodnya". Rossiysko-Arabskiy delovoy sovet [Round Table in the International Information Agency "Russia Today". Russian-Arab Business Council]. Available at: http:// ria.ru/world/20141119/1034178133.html. (accessed November20, 2014).

8. Marokko. TPP PF [Marocco. Chamber of Commerce and Industry of the Russian Federation]. Available at: http://tpprf.ru/ru/vneshnie-svyazy/ vneshnie-svyazy-news/detail/?ID=45644. (accessed August15, 2015).

9. Novosti. Tunis [News. Tunisia]. Zhurnal Mezhdunarodnaya zhizn [International Affairs Journal]. Available at: https://interaffairs.ru/news/ show/11717. (accessed September 3, 2014).

10. Otnosheniya Rossii i Alzhira imeyut osobyy doveritelnyy kharakter [Relations Between Russia and Algeria Have a Special Confidential Nature]. Available at: http://www.council.gov.ru/press-center/ news/42891/. (accessed May 13, 2014).

11. Parfenova A. Marokko gotovitsya rasshiryat sotrudnichestvo s Rossiey [Morocco Is Getting Ready to Expand Cooperation With Russia]. Available at: http://arafnews.ru/news/razmeschenie-biznesa-vmarokko-otkryvaet-rossijskim-investoram-vyhod-naogromnyj-afrikanskij-rynok.html. (accessed October 29, 2014). 